Check for updates

Cite this: RSC Adv., 2017, 7, 49739

Received 26th July 2017

Accepted 16th October 2017

DOI: $10.1039 / \mathrm{c} 7 \mathrm{ra0} 8239 \mathrm{~h}$

rsc.li/rsc-advances

\section{Flexible and high capacity lithium-ion battery anode based on a carbon nanotube/ electrodeposited nickel sulfide paper-like composite $\uparrow$}

\author{
Peng Fan, ${ }^{a}$ Hao Liu, (D) *bcd Libing Liao, ${ }^{\text {a }}$ Jinzhou Fu, ${ }^{a}$ Zhen Wang, ${ }^{b}$ Guocheng Lv, ${ }^{a}$ \\ Lefu Mei, ${ }^{a}$ Huiying Hao, ${ }^{b} J^{2}$ Xing $^{b}$ and Jingjing Dong ${ }^{b}$
}

\begin{abstract}
The integration of flexible carbon-based materials and high capacity anode materials is an effective route to obtain superior flexible electrode materials. In this work, nickel sulfide nanoparticles were electrodeposited on a CNT thin film to form a paper-like composite (NS@CNT). As a binder-free flexible Li-ion battery anode, a record specific capacity to date of $\sim 845 \mathrm{~mA} \mathrm{~h} \mathrm{~g}^{-1}$ at a current density of $60 \mathrm{~mA} \mathrm{~g}^{-1}$ in terms of the mass of the composite has been achieved. The high capacities were mainly attributed to reversible conversion reactions of nickel sulfide and the capacitance effect of the nanostructured composite.
\end{abstract}

\section{Introduction}

In recent years, flexible and wearable power storage devices have been urgently needed with the rapid development of flexible and wearable electronics, such as flexible displays, smart clothes, electronic skins, bendable smart phones and implantable medical devices. ${ }^{1}$ Among the flexible power storage devices, flexible Li-ion batteries (LIBs) have drawn great attention because of their high energy densities. Flexible anodes are essential for obtaining such flexible LIBs. Carbon-based materials including carbon fibers, ${ }^{2,3}$ carbon nanotubes (CNTs) ${ }^{4,5}$ and graphene ${ }^{6}$ are flexible and lithium-active, leading to their wide use as flexible LIB anodes. Nevertheless, the capacities of these materials are generally lower than $600 \mathrm{~mA} \mathrm{~h} \mathrm{~g}{ }^{-1,7,8}$ which cannot meet the demand of the rapid development of flexible electronic devices.

Integration of flexible carbon-based materials and high capacity anode materials (such as transition-metal oxides or transition-metal sulfides) without binders/additives can improve the capacity effectively. ${ }^{\mathbf{4 , 5}, \mathbf{9}-12}$ Among the carbon-based materials, CNTs are good candidates as flexible current collectors for LIBs due to their extremely high specific surface area, robust mechanical properties and excellent electronic conductivity. For

\footnotetext{
${ }^{a}$ School of Materials Science and Technology, China University of Geosciences, Beijing, 100083, P. R. China. E-mail: lbliao@cugb.edu.cn

${ }^{b}$ School of Science, China University of Geosciences, Beijing, 100083, P. R. China. E-mail: liuhao1398@cugb.edu.cn

${ }^{c}$ Hubei Key Laboratory of Ferro \& Piezoelectric Materials and Devices, Faculty of Physics \& Electronic Science, Hubei University, Wuhan, 430062, P. R. China

${ }^{d}$ Beijing Key Laboratory of Optical Detection Technology for Oil and Gas, China University of Petroleum, Beijing, 102249, P. R. China

$\dagger$ Electronic supplementary information (ESI) available. See DOI: $10.1039 / \mathrm{c} 7 \mathrm{ra} 08239 \mathrm{~h}$
}

example, Liangbing $\mathrm{Hu}$ et al. demonstrated a new structure of thin, flexible Li-ion batteries using CNT thin films as current collectors, which showed good electrochemical performance., ${ }^{\mathbf{9} 13}$ Shu Luo et al. reported binder-free $\mathrm{LiCoO}_{2} / \mathrm{CNTs}$ for a $\mathrm{Li}$-ion battery, and these binder-free $\mathrm{LiCoO}_{2} / \mathrm{CNT}$ cathodes exhibited high electrical conductivity, great flexibility, high energy density, and outstanding cycling stability. ${ }^{11}$ Lukman Noerochim et al. prepared a free-standing $\mathrm{SWCNT} / \mathrm{SnO}_{2}$ paper electrode as an anode for a Li-ion battery, and the paper electrode showed a high specific discharge capacity and very stable cycling stability. ${ }^{\mathbf{1 2}}$

Nickel sulfide as a promising anode material draws tremendous attention due to its high theoretical capacity and low cost. ${ }^{\mathbf{1 4}}$ The family of nickel sulfides consists of a series of compounds with different ratios of $\mathrm{N}$ to $\mathrm{S}$ elements, including $\mathrm{Ni}_{3} \mathrm{~S}_{2}, \mathrm{Ni}_{6} \mathrm{~S}_{5}$, $\mathrm{Ni}_{7} \mathrm{~S}_{6}, \mathrm{NiS}$, and $\mathrm{NiS}_{2}$. In particular, $\mathrm{Ni}_{3} \mathrm{~S}_{2}, \mathrm{NiS}$, and $\mathrm{NiS}_{2}$ have gained much interest for lithium storage. ${ }^{\mathbf{1 5 - 2 6}}$ However, the large volume change during the charging/discharging processes and the poor electronic conductivity of the nickel sulfide electrode materials can seriously reduce their electrochemical performance. The combination of nickel sulfides with carbon-based materials (graphene, carbon nanotubes, etc.) can effectively improve their electrochemical properties. For example, Abdel Hamid et $a .^{27}$ synthesized graphene-wrapped nickel sulfide nanoprisms, achieving a specific capacity of over $1200 \mathrm{~mA} \mathrm{~h} \mathrm{~g}^{-1}$ after 100 cycles. Mahmood et al. ${ }^{28}$ reported a facile hydrothermal approach for the synthesis of a nickel sulfide/nitrogen-doped graphene composite electrode, which dramatically improved the electrochemical properties of nickel sulfide.

The LIB electrode made by the traditional tape-casting on a flat current collector method cannot meet the requirements of such flexible electronic devices. Therefore, alternative methods which are suitable for the fabrication of flexible battery 
electrodes need to be developed urgently. Electrodeposition can directly anchor electroactive materials on current collectors without using polymer binders or conducting agents, ensuring good attachment of the active materials on the flexible current collectors. Moreover, it can be used in industry with facile operation and low cost.

In the present work, nickel sulfide was electrodeposited on a CNT thin film to form a composite (NS@CNTs) as a binderfree flexible anode material for LIBs. The special interspace structure of the CNT thin film can effectively accommodate the volume expansion of the nickel sulfide during charge/discharge cycling. Therefore, the NS@CNT composite electrode exhibited high lithium-storage capacity and remarkable capacity retention performance. Moreover, the origin of the additional capacities that often exist in transition-metal sulfide electrodes is investigated in detail.

\section{Experimental section}

\subsection{Chemicals}

All the chemical reagents in this study are of analytical grade, including nickel chloride $\left(\mathrm{NiCl}_{2} \cdot 6 \mathrm{H}_{2} \mathrm{O}\right.$, Beijing Chemical Works) and thiourea $\left(\mathrm{H}_{2} \mathrm{NCSNH}_{2}\right.$, Beijing Chemical Works). The CNT thin film was purchased from Suzhou Hengqiu Graphene Technology Co., Ltd. All aqueous solutions were prepared with deionized (DI) water.

\subsection{Preparation of NS@CNTs}

A piece of $1 \mathrm{~cm} \times 1.5 \mathrm{~cm}$ CNT thin film (a CNT thin film with a thickness of $\sim 20 \mu \mathrm{m}$ ) was clipped and cleaned by ethanol and deionized water several times, followed by drying at $60{ }^{\circ} \mathrm{C}$ for $12 \mathrm{~h}$ under vacuum. The electrodeposition solution was composed of $0.1 \mathrm{M}$ nickel chloride hexahydrate and $1.5 \mathrm{M}$ thiourea. In order to overcome the poor hydrophilicity of the CNT thin film in aqueous electrolyte, a small amount of ethanol was added to the electrolyte. Before the deposition, the CNT thin film was placed into the electrolyte and ultrasonic radiation was applied for $5 \mathrm{~min}$. Then, the deposition was conducted with a pulse voltage method at room temperature using an electrochemical workstation (Ivium-Vertex, Vium Technologies, Holland). The CNT thin film was fixed onto the working electrode, and a $\mathrm{Pt}$ sheet and $\mathrm{Ag} / \mathrm{AgCl}$ electrode served as the counter electrode and the reference electrode, respectively. During the pulse deposition, the low voltage was set at $-0.9 \mathrm{~V}$ and kept for 0.5 seconds, and the high voltage was set at $-0.5 \mathrm{~V}$ and kept for 1 second. After electrodeposition, the NS@CNT composite was removed from the deposition bath, washed with deionized water and dried at $60{ }^{\circ} \mathrm{C}$ for $12 \mathrm{~h}$ under vacuum. The mass loading of the deposit can be controlled by changing the deposition cycles. In the present work, the mass loading was in the range of $\sim 1-2 \mathrm{mg} \mathrm{cm}^{-2}$.

\subsection{Characterization}

The NS@CNT composite was characterized by X-ray diffraction (XRD, D8 Advance, Bruker, Germany) with $\mathrm{Cu} \mathrm{K} \alpha$ radiation $(\lambda=1.5406 \AA$ ) and X-ray photoelectron spectroscopy (XPS,
ESCALab250, Thermo Scientific, American) with monochromatic $150 \mathrm{~W}$ Al $\mathrm{K} \alpha$ radiation. The morphology was investigated by scanning electron microscopy (FESEM, MERLIN VP Compact, ZEISS, Germany) equipped with energy-dispersive spectroscopy (EDS). Transmission electron microscopy (TEM, JEOL 2010F, Japan) was also carried out for the microstructural investigation of the sample.

\subsection{Electrochemical measurements}

The electrochemical performance was evaluated using CR2032 coin cells assembled in a high-purity argon-filled glove box with the moisture and oxygen content maintained below $0.1 \mathrm{ppm}$. The NS@CNT composite was directly used as the working electrode, and pure lithium foil was used as the counter electrode. The separator was Celgard 2400. The electrolyte was 1.0 $\mathrm{M} \mathrm{LiPF}_{6}$ in ethylene carbonate/ethyl methyl carbonate/ dimethyl carbonate solvent $(1: 1: 1 \mathrm{v} / \mathrm{v} / \mathrm{v}$, Shenzhen Keijing Star Tech. Co.). The cells were aged for $12 \mathrm{~h}$ before measurement. All cyclic voltammetry tests were performed on an electrochemical workstation (Ivium-Vertex, Ivium Technologies, Holland). The galvanostatic charge/discharge tests were carried out using a Battery Testing system (CT-4008, NEWARE, China) with a voltage window of $3.0-0.0 \mathrm{~V}$ vs. $\mathrm{Li}^{+} / \mathrm{Li}$ at room temperature.

\section{Results and discussion}

The NS@CNT composite was electrodeposited by a pulse voltage method in a three-electrode system. Before that, linearsweep voltammetry (LSV) was carried out in three different aqueous electrolytes containing (i) $1.5 \mathrm{M}$ thiourea (TU), (ii) $0.1 \mathrm{M} \mathrm{NiCl}_{2} \cdot 6 \mathrm{H}_{2} \mathrm{O}$ and (iii) $0.1 \mathrm{M} \mathrm{NiCl}_{2} \cdot 6 \mathrm{H}_{2} \mathrm{O}$ with $1.5 \mathrm{M}$ TU. Fig. 1a shows their corresponding cathodic linear-sweep curves. The current density is close to zero in the aqueous electrolyte (i), indicating there are no obvious electrochemical reactions on the surface of the CNTs. As a contrast, an onset potential of $-0.8 \mathrm{~V}$ in the aqueous electrolyte (ii) is observed, corresponding to the electro-reduction of $\mathrm{Ni}^{2+}$ to $\mathrm{Ni}$ metal. Nevertheless, the onset of bulk Ni deposition shifts to $\sim-0.6 \mathrm{~V}$ after introducing TU into the electrolyte containing $\mathrm{NiCl}_{2} \cdot 6 \mathrm{H}_{2} \mathrm{O}$. In addition,
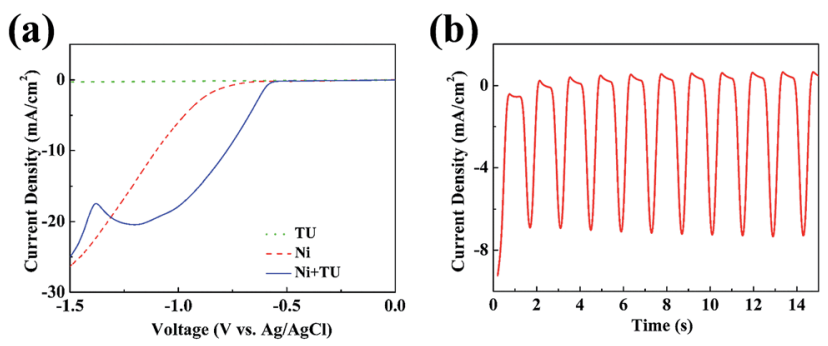

Fig. 1 (a) Linear-sweep voltammetry (cathodic sweep) for CNT thin film substrate in the aqueous electrolytes containing (i) $1.5 \mathrm{M}$ thiourea (TU, green curve), (ii) $0.1 \mathrm{M} \mathrm{NiCl}_{2} \cdot 6 \mathrm{H}_{2} \mathrm{O}$ ( $\mathrm{Ni}$, red curve) and (iii) $0.1 \mathrm{M}$ $\mathrm{NiCl}_{2} \cdot 6 \mathrm{H}_{2} \mathrm{O}$ with $1.5 \mathrm{M}$ thiourea ( $\mathrm{Ni}+\mathrm{TU}$, blue curve). (b) A part of the $1-t$ curve during the pulsed electrodeposition in the aqueous electrolyte containing $0.1 \mathrm{M} \mathrm{NiCl}_{2} \cdot 6 \mathrm{H}_{2} \mathrm{O}$ with $1.5 \mathrm{M}$ thiourea. 
a wide hump around $\neg 1.0-\neg 1.2 \mathrm{~V}$ can be observed, relating to the formation of nickel sulfide. When the TU is added, partial $\mathrm{Ni}^{2+}$ ions are complexed with $\mathrm{TU}$ in the form of $\mathrm{NiCS}\left(\mathrm{NH}_{2}\right)_{2}{ }^{2+}$. Therefore, the possible formation mechanism of the electrodeposited nickel sulfide is as follows: ${ }^{29}$

$$
3 \mathrm{NiCS}\left(\mathrm{NH}_{2}\right)_{2}{ }^{2+}+6 \mathrm{e}^{-} \rightarrow \mathrm{Ni}_{3} \mathrm{~S}_{2}+2 \mathrm{CN}^{-}+2 \mathrm{NH}_{4}{ }^{+}+\mathrm{CS}\left(\mathrm{NH}_{2}\right)_{2}
$$

In order to obtain conformal deposition of nickel sulfide on the CNTs, pulsed electrodeposition was carried out in aqueous electrolyte (iii). The low voltage and the high voltage were selected as $-0.9 \mathrm{~V}$ and $-0.5 \mathrm{~V} v s$. Ag/AgCl during the deposition. A part of the $I-t$ curves during the pulsed electrodeposition is shown in Fig. 1b, showing that the current densities were about $-0.5 \mathrm{~mA} \mathrm{~cm}{ }^{-2}$ and $-7.5 \mathrm{~mA} \mathrm{~cm}^{-2}$, corresponding to the high and low voltages. The mass of $\mathrm{Ni}_{3} \mathrm{~S}_{2}$ is $\sim 1.2 \mathrm{mg}$ when the electrodeposition process is 900 cycles. The weight percentage of $\mathrm{Ni}_{3} \mathrm{~S}_{2}$ in the composite is $\sim 67 \%$.

Fig. 2a displays photographs of the as-prepared NS@CNT composites at 0 degree bending, 180 degree bending and in the curled state. The composite shows excellent flexibility during bending tests, and could even be restored to its original form after being curled up into a ball. During these tests, no nickel sulfide particles dropped out from the CNT thin film, revealing that the electrodeposited nickel sulfides firmly anchor onto the flexible CNT thin film.

Fig. 2b shows XRD patterns of the CNT thin film and the NS@CNT composite. These two XRD patterns are the same, and the diffraction peaks at $2 \theta=26^{\circ}$ can be assigned to the CNT thin film. These results indicate that the as-deposited nickel sulfide is amorphous, which is consistent with other reports. ${ }^{30,31}$

Fig. 2c displays SEM images of the CNT thin film and the NS@CNT composite, respectively. The CNT thin film is composed of interlaced CNTs with an average diameter of (a)

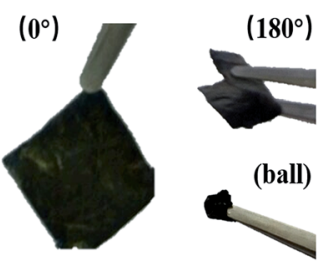

(c)

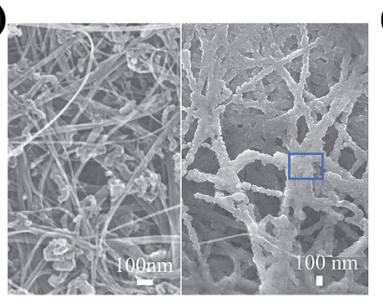

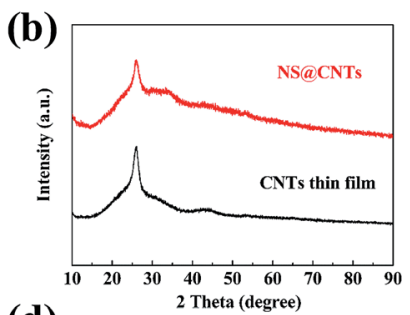

(d)

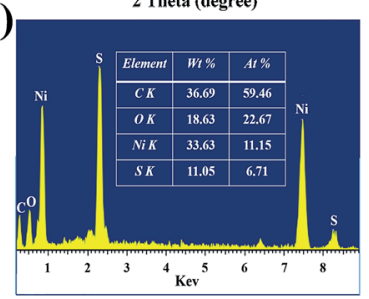

Fig. 2 (a) Photographs of the as-prepared NS@CNT composite at 0 degree bending, nearly 180 degree bending and the curled state. (b) XRD patterns of the CNT thin film and the NS ACNT composite. (c) SEM images taken from the CNT thin film and the NS@CNT composite. (d) EDS of the NS@CNT composite. $\sim 30 \mathrm{~nm}$, and there are a lot of interspaces between the CNTs. It is obvious that the nickel sulfide was deposited on the porous nanostructured CNT thin film. The average diameter after deposition increases to $\sim 100 \mathrm{~nm}$. In addition, the porous structure of the CNT thin film is maintained. Fig. $2 \mathrm{~d}$ shows the corresponding EDS of the selected area of the NS@CNT composite, indicating that the atomic ratio of $\mathrm{Ni}$ and $\mathrm{S}$ elements is $11.15: 6.71$. According to the values, the as-deposited nickel sulfide may be $\mathrm{Ni}_{3} \mathrm{~S}_{2}$, which is consistent with the results reported in the literature. ${ }^{30,32}$ Moreover, the atomic percentage of the element $\mathrm{O}$ is up to $22.67 \%$, indicating that a certain amount of oxides exists in the NS@CNT composite.

In order to reveal more information about the NS@CNT composite, TEM was carried out, and the results are shown in Fig. 3. The wire-like bright contrast in the core observed in Fig. 3a corresponds to the CNTs, and the nickel sulfide is uniformly deposited on the wall of the CNTs to form a coreshell structure. The spatial distributions of all of the elements are disclosed by EDS mapping (Fig. $3 \mathrm{c}-\mathrm{g}$ ), revealing that the deposit is composed of $\mathrm{Ni}, \mathrm{S}$ and $\mathrm{O}$ elements.

XPS measurements were carried out to analyze the surface chemical composition of the synthesized NS@CNT composite. Fig. 4a shows the XPS survey spectra of the sample cleaned by $\mathrm{Ar}$ sputtering at $0 \mathrm{~s}$ (NS-No-Ar), $200 \mathrm{~s}$ (NS-Ar-200 s) and $400 \mathrm{~s}$ (NS-Ar$400 \mathrm{~s}$ ), revealing the presence of $\mathrm{Ni}, \mathrm{O}, \mathrm{C}$ and $\mathrm{S}$ elements in this composite. After Ar sputtering for $400 \mathrm{~s}$, the relative intensity of $\mathrm{O}$ 1s decreased from $\sim 78 \%$ to $\sim 44 \%$ compared to that of the pristine sample. Meanwhile, the relative intensity of $S 2 p$ increased to $\sim 14 \%$. Fig. $4 \mathrm{~b}-\mathrm{d}$ are the fine spectra of the Ni, O and $\mathrm{S}$ elements, showing the evolution of these elements in the cleaning processes. The Ni $2 p$ peaks are always characterized by a complex shape due to the presence of spin-orbit doublet and satellite peaks. In Fig. 4b, two peaks at $855.6 \mathrm{eV}$ and $852.6 \mathrm{eV}$ come from Ni $2 \mathrm{p}_{3 / 2}$ and the peaks at $873.3 \mathrm{eV}$ and $869.5 \mathrm{eV}$ are from $\mathrm{Ni} 2 \mathrm{p}_{1 / 2}$, attributed to the $\mathrm{Ni}$ in oxides/hydroxides and nickel sulfide, respectively. The other peaks at $879.5 \mathrm{eV}$ and $861 \mathrm{eV}$ can be assigned to their satellite peaks. The abundant existence of nickel oxide/hydroxide may be due to the fast oxidation of the fresh sample in air, which was difficult to avoid. ${ }^{31,33}$ After $\mathrm{Ar}$
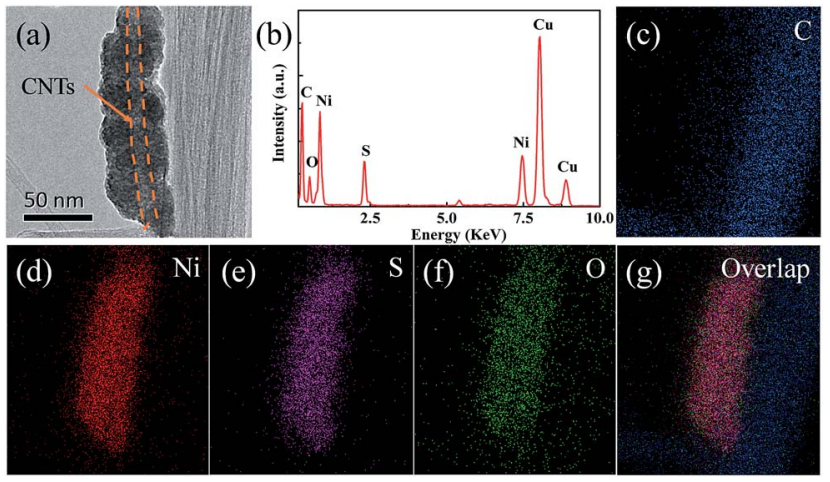

Fig. 3 (a) TEM image and (b) corresponding EDS of the NS@CNT composite. (c)-(g) Element spatial distributions (EDS) taken from the sample shown in (a) for elements of (c) $\mathrm{C}$; (d) Ni; (e) S; (f) $\mathrm{O}$ and (g) the overlap of these elements. 
(a)
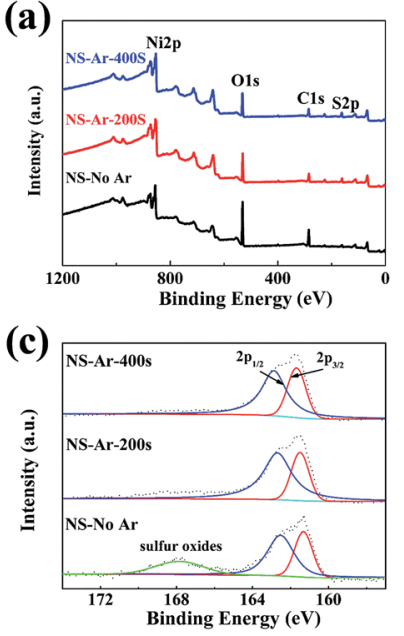

(b)

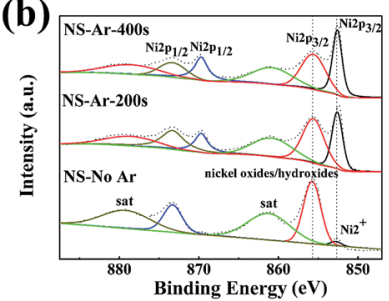

(d)

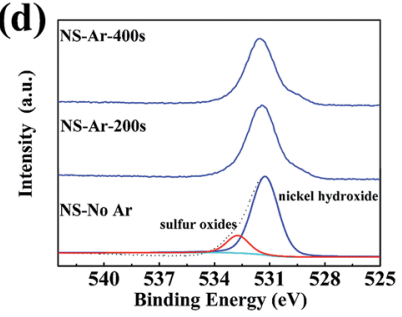

Fig. 4 XPS spectra taken from the NS@CNT composite cleaned by $\mathrm{Ar}$ sputtering at $0 \mathrm{~s}$ (NS-No-Ar), $200 \mathrm{~s}$ (NS-Ar-200 s), and $400 \mathrm{~s}$ (NS-Ar400 s). (a) Survey scan, (b) Ni 2p, (c) S 2p, and (d) O 1s fine scan spectra.

sputtering, the relative intensity of the peaks at $852.6 \mathrm{eV}$ and $869.5 \mathrm{eV}$ relative to nickel sulfide dramatically increases, while the others at $855.6 \mathrm{eV}$ and $873.3 \mathrm{eV}$ relative to oxides/hydroxides become weaker, resulting from the removal of the surface oxide layer on the deposited nickel sulfide sample. Nevertheless, the peaks relative to the hydroxides still exist, indicating the formation of nickel hydroxide in the electrodeposition process. ${ }^{32}$ In addition, three peaks at around $162.5 \mathrm{eV}, 161.5 \mathrm{eV}$ and $168 \mathrm{eV}$ (Fig. 4c) correspond to $\mathrm{S} 2 \mathrm{p}_{1 / 2}, \mathrm{~S} 2 \mathrm{p}_{3 / 2}$ and sulfur oxides in the NSNo-Ar sample, revealing that most of the $\mathrm{S}$ species exist as $\mathrm{S}^{2-}$. After Ar sputtering, the peak related to sulfur oxides disappears, confirming the existence of surface oxidation..$^{31}$ Fig. $4 \mathrm{~d}$ shows the $\mathrm{O}$ 1s peaks at around $531.2 \mathrm{eV}$ and $532.7 \mathrm{eV}$ in the NS-No-Ar sample, which represent the $\mathrm{BE}$ value of $\mathrm{Ni}$ hydroxide and sulfur oxides, respectively. After Ar sputtering, the peak at $532.7 \mathrm{eV}$ relative to the sulfur oxides disappears. At the same time, the relative intensity of the peak at $531.2 \mathrm{eV}$ relative to $\mathrm{Ni}$ hydroxide becomes weaker but still exists, indicating that $\mathrm{Ni}$ hydroxide remains even after the surface layer is removed.

Cyclic voltammetry (CV) curves of the NS@CNT composite are shown in Fig. 5a. In the first cathodic scan, a strong and wide reduction peak at $\sim 0.7 \mathrm{~V} v s . \mathrm{Li}^{+} / \mathrm{Li}$ is attributed to the conversion reaction of $\mathrm{Ni}_{3} \mathrm{~S}_{2}$ to $\mathrm{Li}_{2} \mathrm{~S}$ and $\mathrm{Ni}^{18}$ and the formation of the solid-electrolyte interphase (SEI) layer on the surface of the electrode due to electrolyte decomposition. ${ }^{19}$ The strong oxidation peak at $\sim 2.4 \mathrm{~V} v s$. $\mathrm{Li}^{+} / \mathrm{Li}$ in the first anodic scan corresponds to the reversible conversion reaction of $\mathrm{Li}_{2} \mathrm{~S}$ and $\mathrm{Ni}$ to $\mathrm{Ni}_{3} \mathrm{~S}_{2},{ }^{18,19}$ and the weak oxidation peak at $\sim 1.9 \mathrm{~V} v s . \mathrm{Li}^{+} / \mathrm{Li}$ may be attributed to partial oxidation of the SEI layer. In the subsequent two scans, a couple of redox peaks at $\sim 1.3 \mathrm{~V}$ and $\sim 2.3 \mathrm{Vvs.} \mathrm{Li}^{+} / \mathrm{Li}$ can be observed, which are assigned to the reversible conversion reactions of $\mathrm{Li}$ and $\mathrm{Ni}_{3} \mathrm{~S}_{2}\left(\mathrm{Ni}_{3} \mathrm{~S}_{2}+4 \mathrm{Li}^{+}+\right.$ $\left.4 \mathrm{e}^{-} \leftrightarrow 3 \mathrm{Ni}+2 \mathrm{Li}_{2} \mathrm{~S}\right) .^{14,34}$ In addition, the gap between these two peaks $(1.0 \mathrm{~V})$ is smaller than that in the first scan $(1.7 \mathrm{~V})$, indicating that the electrode polarization decreases after the first lithiation/delithiation process. Moreover, the profiles of the

(a)

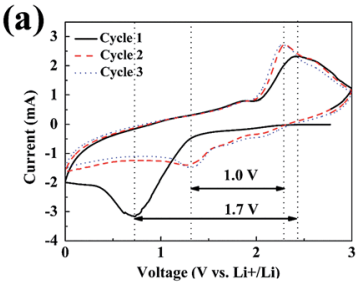

(c)

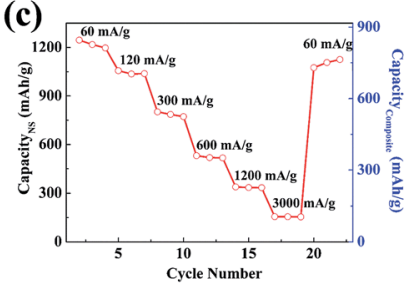

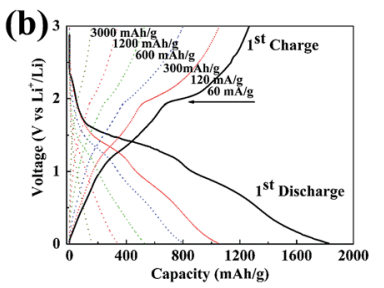

(d)

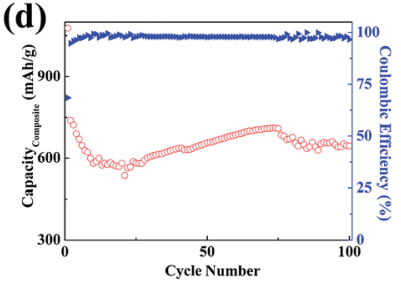

Fig. 5 (a) CV curves of the NS@CNT electrode tested at $0.5 \mathrm{mV} \mathrm{s}^{-1}$. (b) Charge-discharge curves of the NS aCNT electrode at various current densities in the range of $0-3 \vee v s$. $\mathrm{Li}^{+} / \mathrm{Li}$. (c) Rate performance of the NS@CNT electrode. (d) Cycling performance of the NS@CNT electrode at a current density of $300 \mathrm{~mA} \mathrm{~g}^{-1}$.

second and third cycles are similar, reflecting good reversibility of the conversion reactions on the NS@CNT electrode. Fig. 5b shows the galvanostatic charge-discharge curves of the NS@CNT composite electrode at various current densities. In general, the discharging and charging voltage plateaus mainly appear at $\sim 2.0 \mathrm{~V}$ and $\sim 1.2 \mathrm{~V} v s . \mathrm{Li}^{+} / \mathrm{Li}$, which correspond to the reversible conversion reaction of $\mathrm{Li}$ and $\mathrm{Ni}_{3} \mathrm{~S}_{2}$. The first discharging and charging capacities tested at a current density of $60 \mathrm{~mA} \mathrm{~g}^{-1}$ in terms of the mass of the nickel sulfide are $1827 \mathrm{~mA} \mathrm{~h} \mathrm{~g}^{-1}$ and $1265 \mathrm{~mA} \mathrm{~h} \mathrm{~g}^{-1}$, with an initial coulombic efficiency of $\sim 69 \%$. The high irreversible capacity loss may result from the decomposition of the electrolyte to form the SEI layer. Fig. 5c shows the rate performance of the NS@CNT composite. It exhibits high specific charging capacities of about $1265,1056,801,530,337$, and $155 \mathrm{~mA} \mathrm{~h} \mathrm{~g}^{-1}$ in terms of the mass of the nickel sulfide only and about $845,717,544,360,228$ and $105 \mathrm{~mA} \mathrm{~h} \mathrm{~g}^{-1}$ in terms of the mass of the composite at current densities of $60 \mathrm{~mA} \mathrm{~g}{ }^{-1}, 120 \mathrm{~mA} \mathrm{~g}^{-1}, 300 \mathrm{~mA} \mathrm{~g}{ }^{-1}$, $600 \mathrm{~mA} \mathrm{~g}^{-1}, 1200 \mathrm{~mA} \mathrm{~g}^{-1}$ and $3000 \mathrm{~mA} \mathrm{~g}^{-1}$. The specific capacities of the NS@CNT electrode in terms of the mass of the nickel sulfide decrease with increasing current densities from $60 \mathrm{~mA} \mathrm{~g}^{-1}$ to $3000 \mathrm{~mA} \mathrm{~g}^{-1}$. However, the capacity recovers to $1106 \mathrm{~mA} \mathrm{~h} \mathrm{~g}^{-1}$ when the current density decreases back to $60 \mathrm{~mA} \mathrm{~g}^{-1}$, indicating the good cycle stability of the NS@CNT electrode. Fig. S1 $\uparrow$ shows that the CNT thin film has very low charging capacities at various current densities, indicating that the capacities of the NS@CNT composite are mainly contributed to by the electrodeposited nickel sulfide. We further compared the electrochemical performance of the NS@CNT composite with other reports about nickel sulfide anode materials, and the results are shown in Table S1. $\dagger$ The NS@CNT composite exhibits the highest specific capacities in terms of the total mass of the active materials and the current collector. A record specific capacity reported to date, i.e., $850 \mathrm{~mA} \mathrm{~h} \mathrm{~g}^{-1}$ at a current density of $60 \mathrm{~mA} \mathrm{~g}{ }^{-1}$, has been achieved for nickel 
sulfide-based anodes. The above results reveal the tremendous advantages of the NS@CNT composite as a flexible LIB anode.

Fig. 5d shows the cycling performance of the NS@CNT composite at a current density of $300 \mathrm{~mA} \mathrm{~g}^{-1}$. After the first ten cycles, the specific capacity in terms of the mass of the composite decreases dramatically from $738 \mathrm{~mA} \mathrm{~h} \mathrm{~g} \mathrm{~g}^{-1}$ to $580 \mathrm{~mA} \mathrm{~h} \mathrm{~g}{ }^{-1}$, resulting from the irreversible capacity loss during SEI formation. In the subsequent cycles, the specific capacity increases gradually to $708 \mathrm{~mA} \mathrm{~h} \mathrm{~g}^{-1}$ at the $75^{\text {th }}$ cycle, possibly due to the increase of the surface area of the disintegrated $\mathrm{Ni}_{3} \mathrm{~S}_{2}$ during the charging/discharging processes. Then the specific capacity decreases to $644 \mathrm{~mA} \mathrm{~h} \mathrm{~g}^{-1}$ after 100 cycles. This may be due to the slow loss of active material caused by volume expansion during cycling. The good cycling performance of the electrode mainly originates from the special porous structure of the CNT thin film which could effectively mitigate the volume expansion. A high coulombic efficiency of $\sim 98 \%$ is maintained during the 100 cycles. The above results suggest that the NS@CNT composite could be a promising anode material candidate for flexible LIBs.

The specific capacities of the NS@CNT electrode in terms of the active materials are about $845 \mathrm{~mA} \mathrm{~h} \mathrm{~g}^{-1}$ at a current density of $60 \mathrm{~mA} \mathrm{~g}^{-1}$, much higher than the theoretical capacity $\left(446 \mathrm{~mA} \mathrm{~h} \mathrm{~g}^{-1}\right)$ of nickel sulfide $\left(\mathrm{Ni}_{3} \mathrm{~S}_{2}\right) \cdot{ }^{15}$ In order to understand the origins of the additional capacities, $\mathrm{CV}$ curves were obtained at different scan rates, and the results are shown in Fig. 6a. The relationship between the measured current $(i)$ and the scan rate (v) follows the equations:

$$
\begin{gathered}
i(V)=a v^{b} \\
\lg i(V)=b \lg v+\lg a
\end{gathered}
$$

Here, both $a$ and $b$ are adjustable parameters, and the $b$-values are determined from the slope of the plot of $\log i v s . \log v$. In general, the electrode is controlled by the diffusion process when the $b$-value is 0.5 , while the capacitive response is dominant when the $b$-value is $1.0 .^{35}$ Fig. $6 \mathrm{~b}$ shows the calculated $b$ values for the NS@CNT composite electrode. At the potentials of $0.5 \mathrm{Vvs.} \mathrm{Li}^{+} / \mathrm{Li}$ and $1.3 \mathrm{~V} v s . \mathrm{Li}^{+} / \mathrm{Li}$ for the cathodic process, the $b$-values are very close to 0.5 , which indicates that the charge storage mainly comes from the conversion reaction. At the potentials of $0.2 \mathrm{~V} v s . \mathrm{Li}^{+} / \mathrm{Li}$ and $1 \mathrm{~V} v s . \mathrm{Li}^{+} / \mathrm{Li}$, the $b$-values are close to 0.7 , which indicates that parts of the capacities come from capacitive effects. During the anodic process, the $b$-values
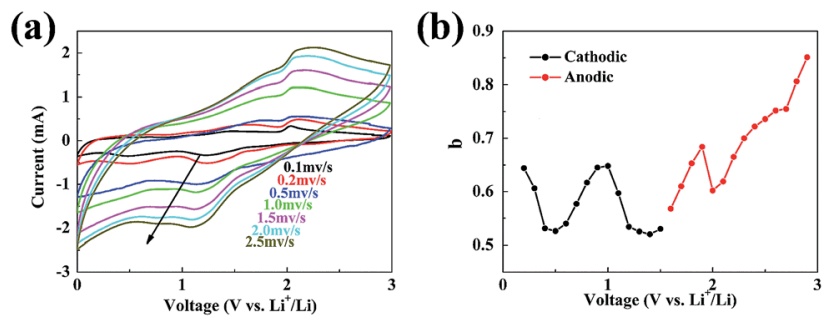

Fig. 6 (a) Typical CV curves at various scan rates for the NS@CNT electrode. (b) Calculated $b$-values as a function of voltage for cathodic and anodic sweeps for the NS@CNT electrode. are in the range of $0.55-0.85$, also indicating that the capacitance effect makes an additional contribution to the total capacity of the NS@CNT composite electrode (especially in the high voltage regions). The above capacitive effects may arise from surface adsorption of Li ions on the NS@CNT composite, ${ }^{36}$ which may form a double-layer capacitor on the surface of the electrode.

\section{Conclusions}

In summary, a flexible NS@CNT composite as a binder-free LIB anode was synthesized through a facile electrodeposition method. The composite electrode exhibited a record specific capacity of $\sim 845 \mathrm{~mA} \mathrm{~h}^{-1}$ in terms of the mass of the composite (including active materials and CNT current collector) at a current density of $60 \mathrm{~mA} \mathrm{~g}^{-1}$. Moreover, its specific capacity remained at $\sim 644 \mathrm{~mA} \mathrm{~h} \mathrm{~g}^{-1}$ after 100 cycles at a current density of $300 \mathrm{~mA} \mathrm{~g}{ }^{-1}$, revealing the good cycling stability of this composite. The high capacities were mainly contributed to by the reversible conversion reactions of nickel sulfide and the capacitance effect of the nanostructured composite. Therefore, the NS@CNT paper-like composite as an anode material showed great promise for flexible LIBs.

\section{Conflicts of interest}

There are no conflicts to declare.

\section{Acknowledgements}

This work was supported by the National Natural Science Foundation of China (No. 51502271 and 41672044); the Fundamental Research Funds for the Central Universities (No. 2652015186 and 2652015189); and the Open Funds of Hubei Key Laboratory of Ferro and Piezoelectric Materials and Devices (No. 201604).

\section{Notes and references}

1 W. Liu, M. S. Song, B. Kong and Y. Cui, Adv. Mater., 2017, 29, 1603436.

2 S. J. Kim, M. C. Kim, S. B. Han, G. H. Lee, H. S. Choe, D. H. Kwak, S. Y. Choi, B. G. Son, M. S. Shin and K. W. Park, Nano Energy, 2016, 27, 545-553.

3 L. Zhang, Y. Huang, Y. Zhang, H. Gu, W. Fan and T. Liu, Adv. Mater. Interfaces, 2016, 3, 1500467.

4 K. Fu, O. Yildiz, H. Bhanushali, Y. Wang, K. Stano, L. Xue, X. Zhang and P. D. Bradford, Adv. Mater., 2013, 25, 51095114.

5 Z. Chen, J. W. F. To, C. Wang, Z. Lu, N. Liu, A. Chortos, L. Pan, F. Wei, Y. Cui and Z. Bao, Adv. Energy Mater., 2014, 4, 1400207.

6 L. Chen, G. Zhou, Z. Liu, X. Ma, J. Chen, Z. Zhang, X. Ma, F. Li, H. M. Cheng and W. Ren, Adv. Mater., 2016, 28, 510517.

7 G. Zhou, F. Li and H. M. Cheng, Energy Environ. Sci., 2014, 7, 1307-1338. 
8 Y. Fei, D. T. Pham and Y. H. Lee, ChemSusChem, 2015, 8, 2284-2311.

9 L. Hu, H. Wu, M. F. La, Y. Yang and Y. Cui, ACS Nano, 2010, 4, 5843-5848.

10 L. Hu, N. Liu, M. Eskilsson, G. Zheng, J. McDonough, L. Wågberg and Y. Cui, Nano Energy, 2013, 2, 138-145.

11 S. Luo, K. Wang, J. Wang, K. Jiang, Q. Li and S. Fan, Adv. Mater., 2012, 24, 2294-2298.

12 L. Noerochim, J.-Z. Wang, S.-L. Chou, D. Wexler and H.-K. Liu, Carbon, 2012, 50, 1289-1297.

13 L. Hu, J. W. Choi, Y. Yang, S. Jeong, F. La Mantia, L. F. Cui and Y. Cui, Proc. Natl. Acad. Sci. U. S. A., 2009, 106, 2149021494.

14 S. C. Han, K. W. Kim, H. J. Ahn, J. H. Ahn and J. Y. Lee, J. Alloys Compd., 2003, 361, 247-251.

15 X. Rui, H. Tan and Q. Yan, Nanoscale, 2014, 6, 9889-9924.

16 X. Xu, W. Liu, Y. Kim and J. Cho, Nano Today, 2014, 9, 604630.

17 Y. Wang, Q. Zhu, L. Tao and X. Su, J. Mater. Chem., 2011, 21, 9248.

18 D. Li, X. Li, X. Hou, X. Sun, B. Liu and D. He, Chem. Commun., 2014, 50, 9361-9364.

19 W. Duan, W. Yan, X. Yan, H. Munakata, Y. Jin and K. Kanamura, J. Power Sources, 2015, 293, 706-711.

20 T. Takeuchi, H. Sakaebe, H. Kageyama, T. Sakai and K. Tatsumi, J. Electrochem. Soc., 2008, 155, A679-A684.

21 Y. Yamaguchi, T. Takeuchi, H. Sakaebe, H. Kageyama, H. Senoh, T. Sakai and K. Tatsumi, J. Electrochem. Soc., 2010, 157, A630-A635.

22 N. Feng, D. Hu, P. Wang, X. Sun, X. Li and D. He, Phys. Chem. Chem. Phys., 2013, 15, 9924-9930.
23 J. Wang, S. Y. Chew, D. Wexler, G. X. Wang, S. H. Ng, S. Zhong and H. K. Liu, Electrochem. Commun., 2007, 9, 1877-1880.

24 Z. Zhang, H. Zhao, Q. Xia, J. Allen, Z. Zeng, C. Gao, Z. Li, X. Du and K. Świerczek, Electrochim. Acta, 2016, 211, 761767.

25 J. Zhu, Y. Li, S. Kang, X.-L. Wei and P. K. Shen, J. Mater. Chem. A, 2014, 2, 3142-3147.

26 Z. Zhang, H. Zhao, Z. Zeng, C. Gao, J. Wang and Q. Xia, Electrochim. Acta, 2015, 155, 85-92.

27 A. A. AbdelHamid, X. Yang, J. Yang, X. Chen and J. Y. Ying, Nano Energy, 2016, 26, 425-437.

28 N. Mahmood, C. Zhang and Y. Hou, Small, 2013, 9, 13211328.

29 S. W. Chou and J. Y. Lin, J. Electrochem. Soc., 2013, 160, D178-D182.

30 S. W. Chou and J. Y. Lin, J. Electrochem. Soc., 2015, 162, A2762-A2769.

31 H. Sun, D. Qin, S. Huang, X. Guo, D. Li, Y. Luo and Q. Meng, Energy Environ. Sci., 2011, 4, 2630-2637.

32 C. W. Su, J. M. Li, W. Yang and J. M. Guo, J. Phys. Chem. C, 2014, 118, 767-773.

33 F. Loglio, M. Innocenti, A. Jarek, S. Caporali, I. Pasquini and M. L. Foresti, J. Electroanal. Chem., 2010, 638, 15-20.

34 P. Poizot, S. Laruelle, S. Grugeon and J. M. Tarascon, J. Electrochem. Soc., 2002, 149, A1212.

35 K. Cao, L. Jiao, Y. Liu, H. Liu, Y. Wang and H. Yuan, Adv. Funct. Mater., 2015, 25, 1082-1089.

36 F. Beguin and E. Frackowiak, Supercapacitors: Materials, Systems, and Applications, Wiley-VCH, 2013. 